\title{
Application of the Bessel function to compute the air pollutant with the stratification of the atmospheric
}

- Tran Anh Dung ${ }^{1}$

- Chu Thi Hang ${ }^{1}$

- Bui Ta Long ${ }^{2}$

${ }^{1}$ Industrial University of Ho Chi Minh city.

${ }^{2}$ Ho Chi Minh city University of Technology, VNU-HCM

(Manuscript Received on August 01st, 2015, Manuscript Revised August 27th, 2015)

\section{ABSTRACT:}

The Bessel differential equation with the Bessel function of solution has been applied.

Bessel functions are the canonical solutions of Bessel's differential equation. Bessel's equation arises when finding separable solutions to Laplace's equation in cylindrical or spherical coordinates. Bessel functions are important for many problems of

Keywords: Air pollutant, Bessel function, the separation of variable method

\section{INTRODUCTION}

The air pollution modeling often leads to solving the general second order partial differential equations (PDE) [11]. The most commonly equation is steady state atmospheric advection - diffusion equation. The separation of variable method is used to solve the PDE. This method is simpler than the Green function method [8], [10], [9]. The atmospheric advection - diffusion equation is transformed to the Bessel equation, with the solution is Bessel function [1]. In this paper, the authors introduce the applications of Bessel equations to solve atmospheric advection - diffusion. The boundary conditions considering the factors of atmospheric stratification and divided into four main types: Dirichlet (total absorption), Neumann (total reflection), Mixed type I (reflections at the advection-diffusion progress and wave propagation.

In this paper, authors present the analytic solutions of the atmospheric advection-diffusion equation with the stratification of the boundary condition. The solution has been found by applied the separation of variable method and Bessel's equation.

\section{Page 14}

ground, absorption at inversion layer) and Mixed Type II (absorption at the ground, reflections at the inversion layer). This model uses Berliand's profile with the wind speed and diffusion coefficients are described by the power law functions [2], The Berliand's profile is closer to reality than the constants of wind speed and diffusion from Gauss plume model [3], [6]. In other hand, the separation of variable method simpler than the Green function method.

\section{AIR POLLUTANT MODEL}

The atmospheric advection - diffusion equation can be written as

$$
\begin{aligned}
U(z) \frac{\partial C(x, y, z)}{\partial x} & =\frac{\partial}{\partial y}\left(K_{y} \frac{\partial C(x, y, z)}{\partial z}\right) \\
& +\frac{\partial}{\partial z}\left(K_{z} \frac{\partial C(x, y, z)}{\partial z}\right)+S
\end{aligned}
$$


where $\mathrm{x}, \mathrm{y}, \mathrm{z}$ are coordinates in the alongwind, cross wind and vertical directions, $\mathrm{C}$ is the concentration of pollutant from the emission source located at the point (xs, ys, zs), $\mathrm{U}$ is the wind speed in downwind direction, $\mathrm{Ky}$ and $\mathrm{Kz}$ are eddy diffusivities in the crosswind and vertical directions respectively, $S$ is the point source's function.

The point source's function can be described as

$$
S(x, y, z)=Q \delta\left(x-x_{s}\right) \delta\left(y-y_{s}\right) \delta\left(z-z_{s}\right)
$$

Where $\mathrm{Q}$ is the source strength, $\delta$ is the Dirac delta function [7].

The wind speed $U$ and the eddy diffusivity $\mathrm{Kz}$ are depended on the height, which are given as

$$
\begin{aligned}
& U(z)=a z^{\alpha}, a=U\left(z_{r}\right) z_{r}^{-\alpha} \\
& K_{z}(z)=b z^{\beta}, b=K_{z}\left(z_{r}\right) z_{r}^{-\beta}
\end{aligned}
$$

This profile is called Berliand's profile [2].

The boundary conditions can be divided to four case as follows

Table 1. Table of the boundary condition, $h$ is the height of the inversion layer.

\begin{tabular}{|c|l|}
\hline Dirichlet & Mixed type I \\
\hline \multicolumn{1}{|c|}{$C(x, y, z)=0$ at $z=0, z=h$} & $K_{z} \frac{\partial C(x, y, z)}{\partial z}=0$ at $z=0, C(x, y, z)=0$ at $z=h$ \\
\hline Neumann & Mixed type I \\
\hline$K_{z} \frac{\partial C(x, y, z)}{\partial z}=0$ at $z=0, z=h$ & $C(x, y, z)=0$ at $z=0, K_{z} \frac{\partial C(x, y, z)}{\partial z}=0$ at $z=h$, \\
\hline
\end{tabular}

The solution of equation (1) is

$$
\begin{aligned}
& C(x, y, z)=\frac{\exp \left[-y^{2} / 2 \sigma_{y}{ }^{2}(x)\right]}{\sqrt{2 \pi} \sigma_{y}{ }^{2}(x)} C(x, z) \\
& K_{y}=d \sigma_{y}{ }^{2}(x) / 2 d x
\end{aligned}
$$

Where $\sigma_{y}(x)$ is the standard deviation in the crosswind direction [4].

The equation of $C(x, z)$ becomes

$$
\frac{\partial C}{\partial x}=\frac{b}{a} z^{-\alpha} \frac{\partial}{\partial z}\left(z^{\beta} \frac{\partial C}{\partial z}\right)
$$

By using the separation of variables in the form $C(x, z)=X(x) Z(z)$, the solution of the equation (5) is given as

$$
\frac{d X}{d x}+\lambda^{2} X=0
$$

And

$\frac{d}{d z}\left(z^{\beta} \frac{d Z}{d z}\right)+\lambda^{2}\left(\frac{a}{b}\right) z^{\alpha} Z=0$

Where $\lambda$ is the constant depend on the boundary conditions.
The solution of the equation (6) with the constant A, which depend on the boundary condition is given as

$$
X(x)=A \exp \left(-\lambda^{2} x\right)
$$

The solution of the equation (7) depend on the boundary conditions of the atmospheric advection-diffusion equation. In this paper, the authors present the scheme to solve equation (7) with the Dirichlet boundary condition. The form of the Dirichlet boundary condition of the equation (7) is

$$
Z=0 \text { at } z=0, z=h
$$

Setting a non-zero value of $\lambda$, then transform variables as $t=z^{(\alpha-\beta+2) / 2}$ ,$Z(z)=z^{(1-\beta) / 2} G(t)$, the equation (7) becomes

$$
t^{2} G^{\prime \prime}+t G^{\prime}+\left(k^{2} t^{2}-\mu^{2}\right) G=0
$$

The equation (10) is the Bessel equation with the solution is given as

$$
G(t)=B_{1} J_{\mu}(k t)+B_{2} J_{-\mu}(k t)
$$


Where $J_{\mu}(z)$ is the Bessel function in order $\mu$ of variable $z$.

$$
\begin{aligned}
& \tau=\alpha-\beta+2 \\
& A_{n}=\frac{J_{\mu}\left[\gamma_{n}(z / h)^{\tau / 2}\right] J_{\mu}\left[\gamma_{n}\left(z_{s} / h\right)^{\tau / 2}\right]}{J_{\mu+1}^{2}\left(\gamma_{n}\right)}
\end{aligned}
$$

And $\gamma_{n}$ given as

$$
J_{\mu}\left(\gamma_{n}\right)=0
$$

In other case of boundary condition, the solutions of the advection- diffusion equation can be found with similar schemes. The concentration of pollutant are obtained in follows table

Where

\begin{tabular}{|c|c|}
\hline $\begin{array}{l}\text { Boundary } \\
\text { condition }\end{array}$ & The concentration of pollutant \\
\hline Dirichlet & $\begin{array}{l}C(x, y, z)=\frac{Q \exp \left[-y^{2} / 2 \sigma_{y}^{2}(x)\right]}{\sqrt{2 \pi} \sigma_{y}} \frac{\tau}{a h^{\tau}}\left(z z_{s}\right)^{(1-\beta) / 2} \sum_{n=1}^{\infty} A_{n} \exp \left[-\frac{b \tau^{2} \gamma_{n}^{2}\left(x-x_{s}\right)}{8 a h^{\tau}}\right] \\
\text { Where } \\
\tau=\alpha-\beta+2, A_{n}=\frac{J_{\mu}\left[\gamma_{n}(z / h)^{\tau / 2}\right] J_{\mu}\left[\gamma_{n}\left(z_{s} / h\right)^{\tau / 2}\right]}{J_{\mu+1}^{2}\left(\gamma_{n}\right)}, J_{\mu}\left(\gamma_{n}\right)=0\end{array}$ \\
\hline Neumann & $\begin{array}{l}C(x, y, z)=\frac{Q \exp \left[-y^{2} / 2 \sigma_{y}^{2}(x)\right]}{\sqrt{2 \pi} \sigma_{y}} \times\left[\frac{\alpha+1}{a h^{\alpha+1}}+\frac{\tau}{a h^{\tau}}\left(z z_{s}\right)^{(1-\beta) / 2} \sum_{n=1}^{\infty} A_{n} \exp \left[-\frac{b \tau^{2} \gamma_{n}{ }^{2}\left(x-x_{s}\right)}{8 a h^{\tau}}\right]\right] \\
\text { Where } \\
\tau=\alpha-\beta+2, A_{n}=\frac{J_{-\mu}\left[\gamma_{n}(z / h)^{\tau / 2}\right] J_{-\mu}\left[\gamma_{n}\left(z_{s} / h\right)^{\tau / 2}\right]}{J_{-\mu}{ }^{2}\left(\gamma_{n}\right)}, J_{-\mu+1}\left(\gamma_{n}\right)=0\end{array}$ \\
\hline $\begin{array}{l}\text { Mixed } \\
\text { type I }\end{array}$ & $\begin{array}{l}C(x, y, z)=\frac{Q \exp \left[-y^{2} / 2 \sigma_{y}^{2}(x)\right]}{\sqrt{2 \pi} \sigma_{y}} \frac{\tau}{a h^{\tau}}\left(z z_{s}\right)^{(1-\beta) / 2} \sum_{n=1}^{\infty} A_{n} \exp \left[-\frac{b \tau^{2} \gamma_{n}^{2}\left(x-x_{s}\right)}{8 a h^{\tau}}\right] \\
\text { Where } \\
\tau=\alpha-\beta+2, A_{n}=\frac{J_{-\mu}\left[\gamma_{n}(z / h)^{\tau / 2}\right] J_{-\mu}\left[\gamma_{n}\left(z_{s} / h\right)^{\tau / 2}\right]}{J_{-\mu+1}^{2}\left(\gamma_{n}\right)}, J_{-\mu}\left(\gamma_{n}\right)=0\end{array}$ \\
\hline $\begin{array}{l}\text { Mixed } \\
\text { type II }\end{array}$ & $\begin{array}{l}C(x, y, z)=\frac{Q \exp \left[-y^{2} / 2 \sigma_{y}^{2}(x)\right]}{\sqrt{2 \pi} \sigma_{y}} \frac{\tau}{a h^{\tau}}\left(z z_{s}\right)^{(1-\beta) / 2} \sum_{n=1}^{\infty} A_{n} \exp \left[-\frac{b \tau^{2} \gamma_{n}^{2}\left(x-x_{s}\right)}{8 a h^{\tau}}\right] \\
\text { Where } \\
\tau=\alpha-\beta+2, A_{n}=\frac{J_{\mu}\left[\gamma_{n}(z / h)^{\tau / 2}\right] J_{\mu}\left[\gamma_{n}\left(z_{s} / h\right)^{\tau / 2}\right]}{J_{\mu}^{2}\left(\gamma_{n}\right)}, J_{\mu-1}\left(\gamma_{n}\right)=0\end{array}$ \\
\hline
\end{tabular}

Table 2. Table of the concentration pollutant formulas. 


\section{NUMERICAL RESULT}

To illustrate three-dimensional dispersion for a point source, the parameters of the model are setting as follows:

The point source located at $(\mathrm{xs}=10 \mathrm{~m}$, ys $=$ $0 \mathrm{~m}, \mathrm{z} \mathrm{s}=50 \mathrm{~m}$ ) with the strength $\mathrm{Q}=10 \mathrm{mg} / \mathrm{s}$.

The meteorological input parameters are taken from [5], [8]: $\alpha=0.29, \beta=0.45, \mathrm{a}=1.5$ $\left(\mathrm{m}^{1-0.29} / \mathrm{s}\right), \mathrm{b}=0.25\left(\mathrm{~m}^{2-0.45} / \mathrm{s}\right)$ and $\sigma_{y}=0.32 x^{1 /(1+\alpha)}$.

The model prediction for concentrations
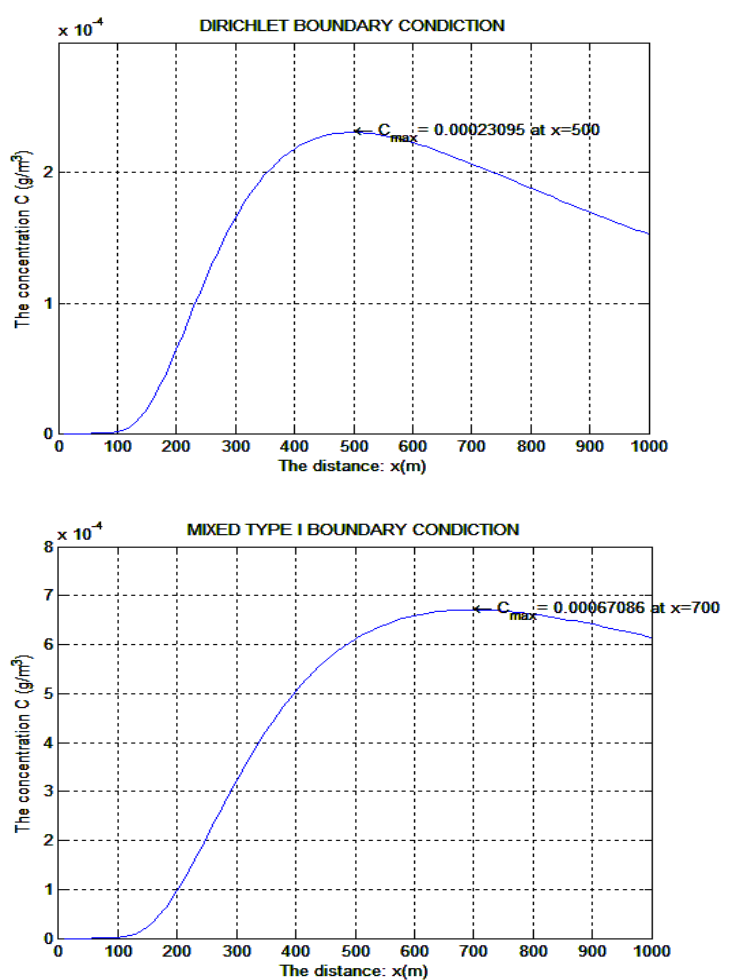

with $\mathrm{z}=1.5 \mathrm{~m}$ (the normalized "breathing level" of Vietnamese). Fig 1 shows the normalized "breathing level" concentrations directly of a point source. First, the concentrations rise and reach to the maximum level, and then begin decreasing because of continued vertical and horizontal spreading. On the other hand, Fig 1 shows the concentration line with boundary condition in the Dirichlet type is similar to the Mixed type II, and the Neumann type is similar to the Mixed type I.
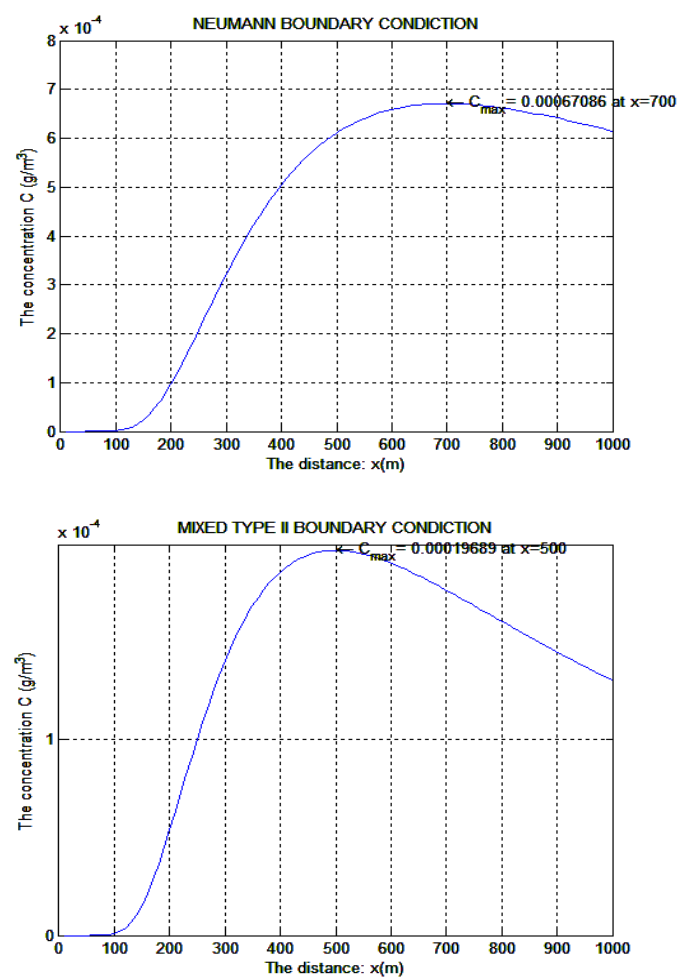

Figure 1. The Variation of normalized breathing level concentration on the center-line $C(x, 0,2 \mathrm{~m})$ with downwind distance from a point source located at $(10,0,50 \mathrm{~m})$.

Fig 1. shows how plumes disperse in horizontal plane. The solid line, dotted line, dashed line and dot-dashed line correspond to the downwind distance of $x=300 \mathrm{~m}, x=600 \mathrm{~m}, x=1200 \mathrm{~m}$ and $x=2400 \mathrm{~m}$ respectively. 


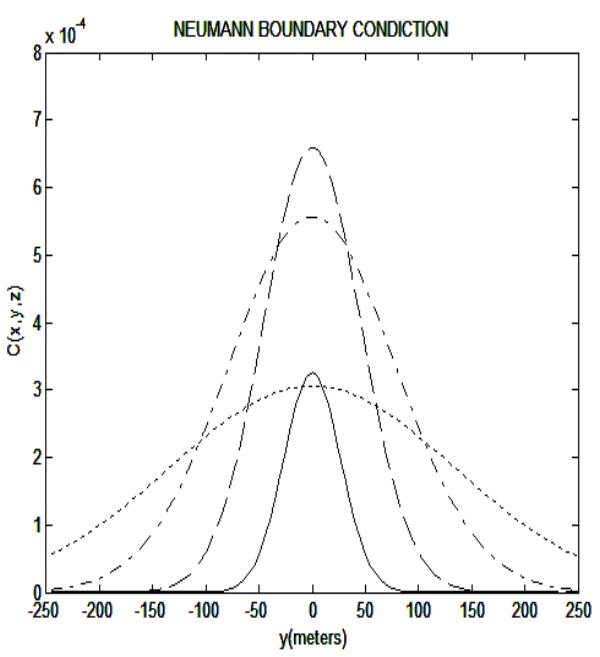

Figure 2 Variation of normalized breathing level concentration $\mathrm{C}(\mathrm{x}, \mathrm{y}, 1.5 \mathrm{~m})$ with crosswind distance due to a point source.

Fig 3 shows how plumes disperse in vertical plane. The solid line, dotted line, dashed line and dot-dashed line correspond to the downwind distance of $x=300 \mathrm{~m}, \mathrm{x}=600 \mathrm{~m}$, $x=1200$ mand $x=2400$ m respectively.

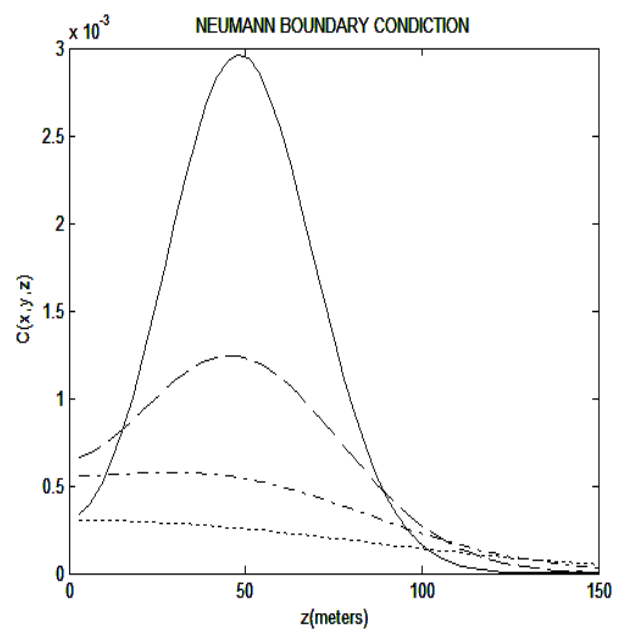

Figure 3 Variation of normalized centerline concentration $\mathrm{C}(\mathrm{x}, 0, \mathrm{z})$ with height due to a point source.

The concentration reach to maximum with $\mathrm{z}$ closed to $z_{s}=50 \mathrm{~m}$.

The resulting contour profiles in the Oxy plane are plotted in Fig 4.

In this study, the analytic solution of equation (14) cannot be found. Therefor, the numerical method is used to approximate the solution. Fig 4 shows the equation (14) always have a solution.

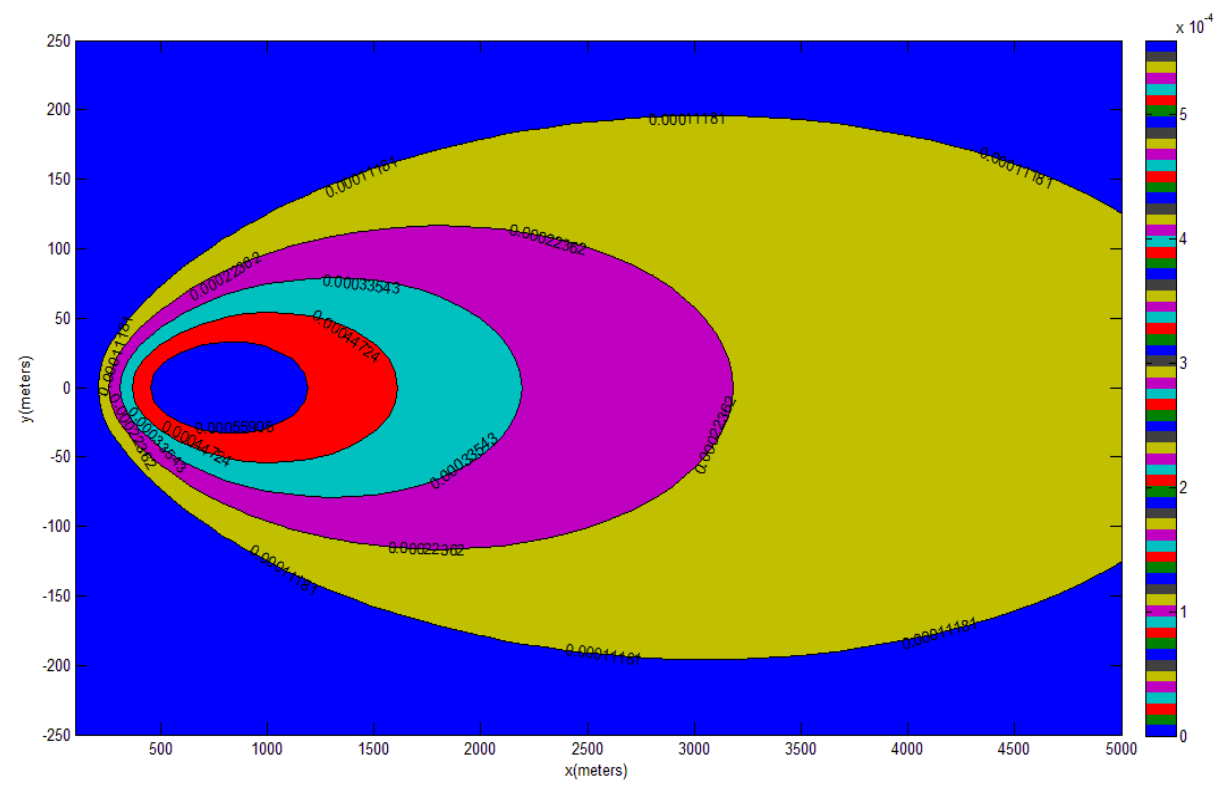

Figure 4 Normalized breathing level concentration contour maps $\mathrm{C}(\mathrm{x}, \mathrm{y}, 1.5 \mathrm{~m})$ in the $\mathrm{Oxy}$ plane from a point source. 


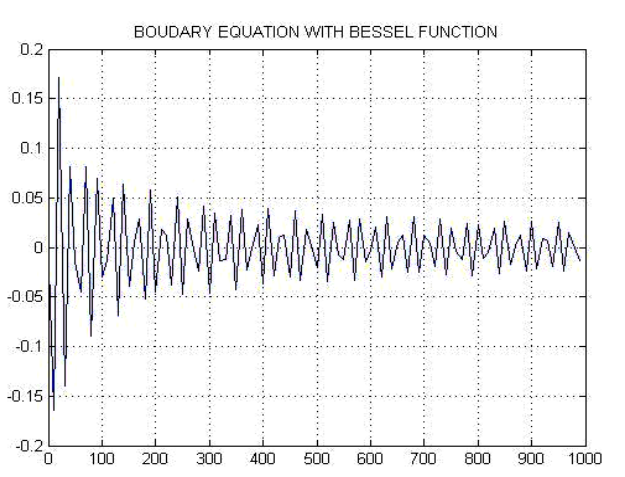

Figure 5. The plot of the Bessel function.

\section{DISCUSSION}

In this study, the analytical dispersion model of air pollutants released from a point source with the inversion layer boundary condition are discussed. These models can be applied to predict the air pollutant for Vietnamese cities.

Acknowledgment: Funding for this research was provided by the National Scientific Program on Climate Changes/11-15, number 38. The authors gratefully acknowledge their financial support for the implementation and completion of this project.

\section{Ứng dụng hàm Bessel để tính các chất gây ô nhiễm không khí với sự phân tầng của khí quyển}

- Trần Anh Dũng ${ }^{1}$

- Chu Thị Hằng ${ }^{1}$

- Bùi Tá Long ${ }^{2}$

${ }^{1}$ Trường Đại học Công nghiệp Thành phố Hồ Chí Minh.

${ }^{2}$ Trường Đại học Bách Khoa, ĐHQG-HCM.

\section{TÓM TÁT:}

Các phương trình vi phân Bessel với các hàm lời giải Bessel đã được áp dụng.

Các hàm Bessel là lời giải kinh điển của phương trình vi phân Bessel. Phương trình Bessel phát sinh khi việc tìm kiếm các lời giải có thể tách rời cho phương trình Laplace trong hệ tọa độ trụ hoặc cầu. Các hàm Bessel rất quan trọng đối với nhiều bài toán về sự tiến triển bình lưu-khuếch tán và sự truyền sóng.

Trong bài báo này, các tác giả trình bày các lời giải giải tích của phương trình bình lưu-khuếch tán trong khí quyển bình lưu-với sự phân tầng của điều kiện biên. Lời giải đã được tìm thấy bằng cách áp dung các phương pháp tách biến và phương trình Bessel.

Từ khóa: Ô nhiễm không khí, hàm Bessel, phương pháp tách biến. 


\section{REFERENCES}

[1]. Abramowitz, M., Stegun I. A., Handbook of Mathematical Functions with Formulas, Graphs, and Mathematical Tables, Dover Publications, New York, 1970..

[2]. Berliand, M. Y., Contemporary problems of atmospheric diffusion and pollution of the atmosphere, Translated version by NERC, U.S.EPA, Raleigh, North Carolina, 1975.

[3]. Calder, K. L., Atmospheric diffusion of particulate material, considered as a boundary value problem, J.Met 18 (1961) 413_416.

[4]. Pasquill, F., Atmospheric dispersion of pollution, Quarterly Journal of the Royal Meteorological Society 97 (1971) 369-395.

[5]. Huang, C. H., On solutions of the diffusion deposition equation for point sources in turbulent shear flow, Journal of Applied Meteorology 38 (1998) 250_254.

[6]. Horst, T. W, A surface depletion model for deposition from a Gaussian plume,
Atmospheric Environment 11 (1977) 41_46.

[7]. Jame, J. F., A Student Guide to Fourier Transforms with Applications in Physics and Engineering, second edition, Cambridge University Press, England, 2002.

[8]. Lin, J. S., Hildemann, L. M., Analytical solutions of the atmospheric diffusion equation with multiple source and heightdependent wind speed and eddy diffusivities, Atmospheric Environment $30 \quad$ (1996) 239_254.

[9]. Seinfeld, J. H., Atmospheric Chemistry and Physics of Air Pollution, Wiley, New York, 1986.

[10].Stakgold, I., Greens Functions and Boundary Value Problems, Wiley, NewYork, 1979.

[11].S. L. Sobolev, A. J. Lohwater, Partial Differential Equations of Mathematical Physics, 1964. 